\title{
Efeito da bactéria diazotrófica em mudas micropropagadas de abacaxizeiros Cayenne Champac em diferentes substratos ${ }^{(1)}$
}

\author{
Olmar Baller Weber ${ }^{(2)}$, Diva Correia( ${ }^{(3)}$, Márcia Regina Souza da Silveira ${ }^{(3)}$, \\ Lindbergue Araújo Crisóstomo(3), Edivaldo Marinho de Oliveira ${ }^{(4)}$ e Eduardo Gomes Sá(4)
}

\begin{abstract}
Resumo - Este trabalho objetivou avaliar o efeito de uma bactéria diazotrófica isolada de abacaxizeiro (Ananas comosus) sobre o crescimento e o acúmulo de nutrientes de mudas micropropagadas da cultivar Cayenne Champac, crescidas em tubetes com diferentes substratos. Os substratos foram: casca de arroz carbonizada, bagana de carnaúba e vermicomposto; casca de arroz carbonizada, pó de coco e vermicomposto; casca de arroz carbonizada, vermiculita e vermicomposto; casca de arroz carbonizada, bagana de carnaúba e vermiculita; casca de arroz carbonizada e pó de coco; e casca de arroz carbonizada e vermiculita. O isolado de bactéria foi identificado pela similaridade (97\% a 98\%) de seqüências de DNAr 16S com a espécie Asaia bogorensis. Após a inoculação do isolado bacteriano nas mudas micropropagadas, estas foram transferidas para os substratos dos tubetes. Aos quatro meses de aclimatação, por ocasião de colheita, as mudas estavam aptas para o plantio no campo. A ocorrência de bactéria diazotrófica relacionada a $A$. bogorensis em abacaxizeiros está sendo apresentada pela primeira vez. $\mathrm{O}$ isolado de bactéria diazotrófica $\mathrm{AB} 219$ propiciou maior taxa de sobrevivência e, no substrato com casca de arroz carbonizada, vermiculita e vermicomposto, maior acúmulo de massa seca de raízes das plantas. O conteúdo de sódio nas mudas foi superior com a inoculação bacteriana, independentemente do substrato.
\end{abstract}

Termos para indexação: Ananas comosus, Asaia bogorensis, inoculação, micropropagação.

\section{Effect of diazotrophic bacteria on pineapple Cayenne Champac plantlets with different substrates}

Abstract - The objective of this work was to evaluate the effect of a diazotrophic bacteria isolated from pineapple (Ananas comosus) plants on plantlets growth and nutrient accumulation of the cultivar Cayenne Champac grown with different substrates in tubules conditions. Treatments consisted of six substrates: carbonized rice hulls + leave dust from carnauba (Copernicia cerifera) palm tree + vermicompost; carbonized rice hulls + rip coir dust + vermicompost; carbonized rice hulls + vermiculite + vermicompost; carbonized rice hulls + leave dust from carnauba palm tree + vermiculite; carbonized rice hulls + ripe coir dust; and carbonized rice hulls + vermiculite. The bacterium isolate was identified by similarity ( $97 \%$ to $98 \%$ ) of sequences of $16 \mathrm{~S}$ rDNA with the species Asaia bogorensis. After the bacterial inoculation, plants were transferred to substrates into tubules conditions. After four months, at harvesting, acclimated plants were ready to be planted in the field. The occurrence of diazotrophic bacteria related to $A$. bogorensis in pineapple plants is presented here for the first time. The bacterial isolate AB219 promoted higher plant surviving onto tubules conditions, and induced higher root weight with the substrate of carbonized rice hulls, vermiculite and vermicompost. Higher sodium contents were detected in bacterized plants, independently of substrates.

Index terms: Ananas comosus, Asaia bogorensis, inoculation methods, micropropagation.

\footnotetext{
(1) Aceito para publicação em 20 de março de 2003.

(2) Embrapa-Centro Nacional de Pesquisa de Monitoramento e Avaliação de Impacto Ambiental, Caixa Postal 69, CEP 13820-000 Jaguariúna, SP. E-mail:weber@cnpma.embrapa.br
}

\footnotetext{
(3) Embrapa-Centro Nacional de Pesquisa de Agroindústria Tropical, Rua Dra. Sara Mesquita, 2270 Planalto Pici, CEP 60511-110 Fortaleza, CE. E-mail: diva@cnpat.embrapa.br, lingerg@cnpat.embrapa.br

(4) Universidade Estadual do Ceará, Av. Parajana, 1700, CEP 60740-000 Fortaleza, CE.
} 


\section{Introdução}

A cultura do abacaxi está amplamente disseminada nos países da região tropical e o Brasil destaca-se como terceiro produtor (FAO, 2002). Em 2001, colheuse pouco mais de 63 mil hectares, o que gerou uma produção de aproximadamente 3,1 milhões de toneladas da fruta (Agrianual, 2002). Como área de cultivo destaca-se a região Nordeste, onde são colhidos anualmente mais de 25 mil hectares. Contudo, a produtividade da cultura na região é considerada baixa por causa da baixa qualidade das mudas (Reinhardt, 1998; Teixeira et al., 2001) e da ocorrência de doenças (Matos, 1987), entre outros fatores que afetam a produtividade e a qualidade dos frutos. De acordo com o último autor, as perdas decorrentes da fusariose, causada pelo fungo Fusarium subglutinans, podem ser superiores a $40 \%$ da produção.

As cultivares Pérola e Smooth Cayenne ocupam as maiores áreas de produção no país e são sensíveis à fusariose, e as mudas constituem a principal fonte de disseminação dessa doença (Matos, 1987). Apesar da micropropagação proporcionar mudas livres de patógenos (Fitchet, 1990; Feuser et al., 2001; Teixeira et al., 2001), não evita que as mudas sejam contaminadas no viveiro e no campo. Além disso, a contaminação pode ocorrer durante a multiplicação in vitro e representa risco quando se trata de patógenos (Leifert \& Cassells, 2001).

A limpeza dos propágulos durante a propagação in vitro pode eliminar também microrganismos que beneficiam a cultura. Recentemente, bactérias diazotróficas têm sido isoladas de abacaxizeiros (Weber et al., 1999; Tapia-Henández et al., 2000). O potencial dessas bactérias na fixação biológica do $\mathrm{N}_{2}$ foi destacado em gramíneas por Döbereiner (1992), e seus benefícios sobre o crescimento de bananeiras foram observados por Weber et al. (2000).

A inoculação de bactérias diazotróficas em mudas micropropagadas de abacaxizeiros seria bastante facilitada na ausência de outros microrganismos do solo. Ademais, os abacaxizeiros micropropagados apresentam crescimento bastante lento durante a fase de aclimatação, que, dependendo do substrato e da nutrição das plantas (Folliot \& Marchal, 1990), pode levar até dez meses. Assim, a aplicação de bactérias diazotróficas e promotoras de crescimento em mudas micropropagadas poderia vir a ser uma alternativa para reduzir o período de aclimatação das mudas.

Substratos alternativos de origem vegetal têm sido recomendados para a produção de mudas e o cultivo de plantas envasadas (Souza, 2001), em substituição ao solo. Esses resíduos poderiam ser misturados à vermiculita, que é amplamente utilizada nos viveiros (Minami, 2000).

O objetivo deste trabalho foi avaliar o efeito de uma bactéria diazotrófica isolada de abacaxizeiro sobre o crescimento e o acúmulo de nutrientes de mudas micropropagadas da cultivar Cayenne Champac, crescidas em tubetes com diferentes substratos.

\section{Material e Métodos}

Mudas micropropagadas de abacaxizeiros Cayenne Champac, obtidas no Laboratório de Cultura de Tecidos da Embrapa-Centro Nacional de Pesquisa de Agroindústria Tropical, em Fortaleza, CE, foram submetidas à inoculação de um isolado de bactéria diazotrófica, oriundo da própria cultura, e cultivadas em tubetes com diferentes substratos, de setembro de 2001 a janeiro de 2002.

$\mathrm{O}$ isolado de bactéria diazotrófica foi obtido de partes aéreas de abacaxizeiros Smooth Cayenne, provenientes de áreas de produção no Município de Mamanguape, PB. $\mathrm{O}$ isolado foi caracterizado pelo crescimento em meios semi-sólidos, contendo os sais de JNFb e as fontes: sacarose, glicose, frutose, galactose, manitol, sorbitol, mesoeritritol $+\mathrm{NH}_{4}{ }^{+}$e $\mathrm{N}$-acetil glucosamina, seguindo-se a metodologia empregada por Weber et al. (1999). A identificação do isolado bacteriano foi realizada, em 2000, na Fundação André Tosello, em Campinas, SP, utilizandose seqüências do gene $16 \mathrm{~S}$ obtidas a partir do DNA genômico. Na amplificação do DNA ribossomal 16S, utilizaram-se os primers (oligonucleotídeos sintéticos) p $27 \mathrm{f} \mathrm{e}$ p1525r e, após a purificação e o seqüenciamento, em equipamento automático, as seqüências foram comparadas com seqüências de DNAr 16S de organismos representados nas bases de dados RDP (Ribossomal Database Project, Wisconsin, USA) e Genbank. O isolado bacteriano encontra-se na coleção de culturas de bactérias de fruteiras da Embrapa-Centro Nacional de Pesquisa de Agroindústria Tropical.

As plântulas foram propagadas no meio MS (Murashige \& Skoog, 1962), suplementado de 0,5 $\mathrm{mg} \mathrm{L}^{-1}$ de ácido naftaleno-acético e $0,5 \mathrm{mg} \mathrm{L}^{-1}$ de 6 -benzilaminopurina, e alongadas no mesmo meio com ausência dos reguladores. Com o alongamento, as plântulas, em 
número de quatro, foram transferidas para frascos tipo maionese, os quais continham $10 \mathrm{~mL}$ da solução $1 / 4$ dos sais de NFb (Döbereiner et al., 1995) e $2 \mathrm{~mL}$ de uma suspensão contendo aproximadamente $4 \times 10^{8}$ células do isolado da bactéria diazotrófica (AB219), em meio líquido Dygs conforme Weber et al. (2000). O tratamento controle foi estabelecido nas mesmas condições dos meios sem a bactéria. $\mathrm{Na}$ ocasião, as plantas tinham em média $1,9 \mathrm{~g}$ de massa de matéria fresca.

Após dois dias de incubação à temperatura ambiente no laboratório, as plântulas foram transferidas para tubetes na casa de vegetação. Os tubetes de $288 \mathrm{~cm}^{3}$ estavam preenchidos com os seguintes substratos: casca de arroz carbonizada, bagana de carnaúba e vermicomposto; casca de arroz carbonizada, pó de coco e vermicomposto; casca de arroz carbonizada, vermiculita e vermicomposto; casca de arroz carbonizada, bagana de carnaúba e vermiculita; casca de arroz carbonizada e pó de coco; casca de arroz carbonizada e vermiculita. Na formulação das misturas utilizaram-se proporções volumétricas $(1: 1: 1$ ou $1: 1)$ de vermiculita de textura média e outros materiais, passados em peneira de $2 \mathrm{~mm}$ da abertura. Os resultados da análise química (Silva, 1999) dos substratos encontram-se na Tabela 1 .

Por ocasião da transferência para os tubetes, os substratos foram umedecidos até próximo da capacidade máxima de retenção de água utilizando-se nebulizadores instalados no interior da casa de vegetação, os quais eram ativados três a quatro vezes ao dia, durante 15 minutos, de forma a assegurar boa umidade nos substratos. Mensalmente, cada tubete contendo uma planta recebeu $8 \mathrm{~mL}$ da solução Hoagland (Hoagland \& Arnon, 1950), modificada em relação ao $\mathrm{N}\left(287,5 \mathrm{mg} \mathrm{L}^{-1}\right)$, utilizando-se como fonte de $\mathrm{N}$ o sulfato de amônio.
Após quatro meses de cultivo, as plantas foram colhidas e avaliadas com os substratos. Quanto à agregação destes às raízes atribuíram-se as seguintes notas: 3 , para uma mistura firme, podendo ser retirado na sua totalidade com as raízes das plantas; 2, para uma mistura medianamente firme, quando havia quebra de torrão e parte do material permanecia no interior do tubete; e 1, para o substrato solto, permanecendo boa parte dele no interior do tubete. Em seguida, porções de aproximadamente $1 \mathrm{~g}$ das raízes de três plantas de cada tratamento foram esterilizadas superficialmente em solução a 1\% de cloramina-T, durante cinco minutos, e passadas várias vezes em água esterilizada e tampão fosfato, para avaliar a colonização de bactérias diazotróficas (Döbereiner et al., 1995). A porção restante das raízes e as partes aéreas das plantas foram secadas a $65^{\circ} \mathrm{C}$ até obter-se peso constante de modo a estabelecer a massa da matéria seca. Os nutrientes foram determinados na parte aérea seca (Silva, 1999).

Os dados foram analisados no delineamento de blocos casualizados em esquema fatorial $(2 \times 6) \times 4$, sendo os fatores representados por dois tipos de inóculo (ausência e presença da bactéria diazotrófica) e seis substratos, com quatro repetições de 18 plantas cada. Os valores das características foram normalizados, submetidos à análise de variância e as médias comparadas pelo teste de Tukey, a $5 \%$ de probabilidade.

\section{Resultados e Discussão}

O isolado de bactéria diazotrófica AB219 utilizado neste trabalho foi identificado pela similaridade (97\% a 98\%) de seqüências do DNAr 16S com a es-

Tabela 1. Análise química dos substratos utilizados na aclimatação das mudas micropropagadas de abacaxizeiros Cayenne Champac.

\begin{tabular}{|c|c|c|c|c|c|c|}
\hline \multirow{2}{*}{$\begin{array}{l}\text { Componente } \\
\text { químico }\end{array}$} & \multicolumn{6}{|c|}{ Substratos $^{(1)}$} \\
\hline & 1 & 2 & 3 & 4 & 5 & 6 \\
\hline $\mathrm{N}\left(\mathrm{g} \mathrm{kg}^{-1}\right)$ & 10,7 & 9,8 & 3,5 & 12,1 & 6,5 & 0,1 \\
\hline $\mathrm{P}\left(\mathrm{g} \mathrm{kg}^{-1}\right)$ & 4,0 & 4,0 & 3,0 & 2,4 & 2,0 & 1,5 \\
\hline $\mathrm{K}\left(\mathrm{g} \mathrm{kg}^{-1}\right)$ & 4,7 & 3,9 & 8,0 & 8,2 & 6,4 & 20,0 \\
\hline $\mathrm{Na}\left(\mathrm{g} \mathrm{kg}^{-1}\right)$ & 6,5 & 6,0 & 7,0 & 7,5 & 7,5 & 10,0 \\
\hline $\operatorname{Mg}\left(\mathrm{g} \mathrm{kg}^{-1}\right)$ & 4,4 & 4,6 & 32,1 & 7,9 & 1,5 & 73,1 \\
\hline $\mathrm{Ca}\left(\mathrm{g} \mathrm{kg}^{-1}\right)$ & 23,7 & 23,9 & 23,9 & 2,7 & 6,6 & 9,3 \\
\hline $\mathrm{S}\left(\mathrm{g} \mathrm{kg}^{-1}\right)$ & 2,7 & 2,6 & 2,9 & 2,6 & 2,7 & 3,4 \\
\hline $\mathrm{Cu}\left(\mathrm{mg} \mathrm{kg}^{-1}\right)$ & 17,7 & 17,0 & 15,0 & 11,0 & 9,6 & 8,0 \\
\hline $\mathrm{Fe}\left(\mathrm{mg} \mathrm{kg}^{-1}\right)$ & $3.448,0$ & $2.757,0$ & $9.495,0$ & $1.172,4$ & 563,6 & $2.002,5$ \\
\hline $\operatorname{Mn}\left(\mathrm{mg} \mathrm{kg}^{-1}\right)$ & 378,0 & 379,8 & 93,2 & 365,4 & 319,8 & 442,2 \\
\hline $\mathrm{Zn}\left(\mathrm{mg} \mathrm{kg}^{-1}\right)$ & 377,4 & 396,1 & 379,2 & 324,6 & 336,0 & 361,2 \\
\hline $\mathrm{pH}\left(\mathrm{CaCl}_{2}, 0,01 \mathrm{M}\right)$ & 6,45 & 6,70 & 7,00 & 5,70 & 5,80 & 6,70 \\
\hline
\end{tabular}

(1) 1: casca de arroz carbonizada, bagana de carnaúba e vermicomposto; 2: casca de arroz carbonizada, pó de coco e vermicomposto; 3: casca de arroz carbonizada, vermiculita e vermicomposto; 4: casca de arroz carbonizada, bagana de carnaúba e vermiculita; 5: casca de arroz carbonizada e pó de coco; 6: casca de arroz carbonizada e vermiculita. 
pécie Asaia bogorensis. A atividade de nitrogenase da bactéria, confirmada pela redução do acetileno em meio semi-sólido JNFb, e sua ocorrência em abacaxizeiro estão sendo apresentadas pela primeira vez. A espécie $A$. bogorensis foi identificada inicialmente em flores de orquídeas, plantas de Plumbago auriculata e arroz fermentado, na Indonésia (Yamada et al., 2000).

Em raízes das mudas do abacaxizeiro que receberam o inóculo bacteriano detectaram-se as maiores populações de bactérias diazotróficas (Tabela 2). Bactérias purificadas desses mesmos tratamentos foram capazes de crescer em meio semi-sólido contendo os sais de $\mathrm{JNFb}$ e várias fontes de carbono: sacarose, glicose, frutose, galactose, manitol, sorbitol, meso-eritritol $+\mathrm{NH}_{4}{ }^{+}$e $\mathrm{N}$-acetil glucosamina, sendo uma fonte em cada meio. A formação de película subsuperficial nos meios e a morfologia das células dessas bactérias eram similares às observadas com a cultura bacteriana utilizada como inóculo. A colonização das plantas pelo AB219 já era esperada, por ser ele oriundo da parte aérea de abacaxizeiros Smooth Cayenne, pertencente ao grupo Cayenne.

As bactérias diazotróficas foram também detectadas, em menor número, nas raízes das plantas con- troles, o que pode ser atribuído à proximidade dos tratamentos na casa de vegetação ou à presença de bactérias, em níveis não detectáveis pela técnica do número mais provável, nos explantes utilizados. A contaminação de plântulas não é rara, mesmo durante a fase de multiplicação in vitro e, conforme Leifert \& Cassells (2001), representa risco maior quando se trata de organismos patogênicos às plantas ou ao homem. A presença de bactérias diazotróficas já foi observada anteriormente em tratamentos controles, com plântulas de arroz (Baldani, 1996) e bananeira (Weber et al., 2000), indicando que esse grupo de bactérias coloniza com certa facilidade as mudas.

Com a inoculação do isolado de bactéria diazotrófica observou-se maior taxa de sobrevivência dos abacaxizeiros (Tabela 2). A morte das plantas estava sempre associada à presença de fungos nas raízes e que podem ter sido introduzidos com os materiais de pó de coco, bagana de carnaúba e vermicomposto; esses fungos não foram detectados em plantas crescidas com a mistura de casca de arroz carbonizada e vermiculita. A utilização de substratos inertes (Souza, 2001) ou desinfestados (Randing et al., 1998; Chaves et al., 2000) tem sido recomendada para a produção de mudas.

Tabela 2. Número mais provável (NMP) de bactérias diazotróficas associadas às raízes das mudas, taxa de sobrevivência das mudas e índice de agregação dos substratos às raízes dos abacaxizeiros Cayenne Champac submetidos à inoculação do isolado de bactéria diazotrófica AB219 e crescidos em diferentes substratos em tubete ${ }^{(1)}$.

\begin{tabular}{|c|c|c|c|c|c|c|c|}
\hline \multirow[t]{2}{*}{ Tratamento } & \multicolumn{6}{|c|}{ Substratos $^{(2)}$} & \multirow[t]{2}{*}{ Média } \\
\hline & 1 & 2 & 3 & 4 & 5 & 6 & \\
\hline \multicolumn{8}{|c|}{ NMP (x10 } \\
\hline Controle & 3,29 & 1,38 & 3,00 & 4,14 & 1,16 & 1,39 & $2,39 \mathrm{~B}$ \\
\hline AB219 & 28,12 & 18,58 & 36,14 & 17,02 & 3,61 & 9,53 & $18,83 \mathrm{~A}$ \\
\hline Média & $15,70 \mathrm{a}$ & $9,98 \mathrm{a}$ & $19,57 \mathrm{a}$ & $10,58 \mathrm{a}$ & $2,39 \mathrm{a}$ & $5,46 a$ & \\
\hline \multicolumn{8}{|c|}{ Taxa de sobrevivência (\%) } \\
\hline Controle & 95,0 & 98,8 & 93,8 & 93,8 & 97,5 & 100,0 & $96,5 \mathrm{~B}$ \\
\hline AB219 & 98,8 & 100,0 & 98,8 & 95,0 & 100,0 & 100,0 & $98,8 \mathrm{~A}$ \\
\hline Média & $96,9 \mathrm{ab}$ & $99,4 a$ & $96,3 \mathrm{ab}$ & $94,4 \mathrm{~b}$ & $98,8 \mathrm{a}$ & $100,0 \mathrm{a}$ & \\
\hline \multicolumn{8}{|c|}{ Índice de agregação de substratos às raízes ${ }^{(3)}$} \\
\hline Controle & 2,25 & 3,00 & 3,00 & 2,25 & 2,50 & 3,00 & $2,67 \mathrm{~A}$ \\
\hline AB219 & 2,50 & 3,00 & 3,00 & 2,25 & 2,50 & 3,00 & $2,71 \mathrm{~A}$ \\
\hline Média & $2,38 b$ & $3,00 \mathrm{a}$ & $3,00 \mathrm{a}$ & $2,25 b$ & $2,50 \mathrm{~b}$ & $3,00 \mathrm{a}$ & \\
\hline $\begin{array}{l}\text { (1) Médias seguida } \\
\text { de NMP, taxa de s } \\
\text { fresca, arco seno } \\
\text { 2: casca de arroz } \\
\text { bagana de carnaúb } \\
\text { firme; 1: solto. }\end{array}$ & sma letra & $\begin{array}{l}\text { la na lin } \\
\text { gregação } \\
\text { tamente, } \\
\text { vermico }\end{array}$ & $\begin{array}{l}\text { úscula na co } \\
\text { tam médias } \\
\text { nálise estatí } \\
\text { 3: casca de a }\end{array}$ & $\begin{array}{l}\text { o diferen } \\
\text { uatro e q } \\
\text { 1: casca } \\
\text { bonizada } \\
\text { ca de arro }\end{array}$ & $\begin{array}{l}\text { a } 5 \% \text { de pr } \\
\text { etições, e fo } \\
\text { carbonizad } \\
\text { lita e verm } \\
\text { izada e vern }\end{array}$ & $\begin{array}{l}\text { de pelo te } \\
\text { formados } \\
\text { a de carna } \\
\text { to; } 4 \text { : casc } \\
\text { 3: torrão }\end{array}$ & $\begin{array}{l}\text { ukey; os d } \\
\mathrm{x} \mathrm{g}^{-1} \text { de ma } \\
\text { ermicomp } \\
\text { z carboni } \\
\text { medianan }\end{array}$ \\
\hline
\end{tabular}


Contudo, em se tratando de resíduos orgânicos, é possível que ocorram contaminações com fitopatógenos no viveiro. A aplicação de compostos orgânicos e a inoculação de microrganismos endofíticos capazes de induzir resistência em mudas poderia ser uma alternativa. A produção de moléculas com atividade contra Rhizoctonia solani (Kang et al., 1998) e outros patógenos (Bevivino et al., 1998; Sfalanga et al., 1999) tem sido observada em estirpes de Burkholderia cepacia. Bactérias diazotróficas relacionadas a esta espécie ocorrem em abacaxizeiros (Weber et al., 1999) e diferem pouco quanto à versatilidade de crescer em substratos com meio semi-sólido em comparação com o AB219 utilizado no presente trabalho.

Foi observada a formação de torrões firmes quando foram usadas as misturas de casca de arroz carbonizada, pó de coco e vermicomposto; casca de arroz carbonizada, vermiculita e vermicomposto; e casca de arroz carbonizada e vermiculita, esta com maior facilidade de ser retirada do tubete (Tabela 2). De acordo com Souza (2001), a característica de agregação às raízes deve ser levada em conta na escolha do substrato.

Aos quatro meses, as plantas estavam aptas para serem transplantadas para o campo (Tabelas 3 e 4). $\mathrm{O}$ período de aclimatação de mudas micropropagadas do abacaxizeiro, de acordo com Teixeira et al. (2001), leva de seis a oito meses, e dependendo do substrato e da nutrição das plantas (Folliot \& Marchal, 1990), pode levar até dez meses.
A inoculação do AB219 favoreceu o crescimento de raízes das plantas que foram crescidas com a mistura de casca de arroz carbonizada, vermiculita e vermicomposto (Tabela 3). No entanto, houve incremento não-significativo do acúmulo de matéria seca da parte aérea $(9,4 \%)$ e total $(13,1 \%)$ neste substrato, em relação às plantas controles.

Entre os substratos, a mistura da casca de arroz carbonizada com pó de coco proporcionou o pior desempenho às mudas (Tabela 3 ), o que pode ser atribuído à má agregação física (Tabela 2) e a uma possível limitação de nutrientes e pouca retenção de água. Baixa relação $\mathrm{C}$ : N foi observada no pó de casca de coco verde (Rosa et al., 2001), bem como baixa retenção de água em pequenos blocos da casca de coco seco, na comparação com pó de xaxim (Demattê \& Demattê, 1996). O baixo conteúdo de nutrientes da parte aérea das plantas crescidas com a mistura de casca de arroz carbonizada e pó de coco (Tabela 4) pode estar relacionado à limitação nutricional das plantas, em comparação com os substratos que tinham o vermicomposto em sua composição.

A inoculação do AB219 propiciou maior acúmulo de $\mathrm{Na}$ nas plantas, independentemente do substrato; de $\mathrm{Mg}$, com a mistura de casca de arroz carbonizada, bagana de carnaúba e vermicomposto; de $\mathrm{Ca}$, com a mistura de casca de arroz carbonizada, vermiculita e vermicomposto (Tabela 4). O aumento do $\mathrm{Na}(60 \%$ a $110 \%$ ) superou em muito o de matéria seca na parte

Tabela 3. Acúmulo de matéria seca das mudas micropropagadas de abacaxizeiros Cayenne Champac submetidas à inoculação do isolado de bactéria diazotrófica AB219 e crescidas em diferentes substratos em tubete ${ }^{(1)}$.

\begin{tabular}{|c|c|c|c|c|c|c|}
\hline \multirow[t]{2}{*}{ Tratamento } & \multicolumn{6}{|c|}{ Substratos $^{(2)}$} \\
\hline & 1 & 2 & 3 & 4 & 5 & 6 \\
\hline & \multicolumn{6}{|c|}{ Matéria seca de raízes (g por planta) } \\
\hline Controle & $0,26 \mathrm{Ab}$ & $0,26 \mathrm{Ab}$ & $0,30 \mathrm{Bab}$ & $0,19 \mathrm{Ab}$ & $0,22 \mathrm{Ab}$ & $0,43 \mathrm{Aa}$ \\
\hline \multirow[t]{2}{*}{ AB219 } & $0,21 \mathrm{Ab}$ & $0,25 \mathrm{Ab}$ & $0,45 \mathrm{Aa}$ & $0,16 \mathrm{Ab}$ & $0,24 \mathrm{Ab}$ & $0,45 \mathrm{Aa}$ \\
\hline & \multicolumn{6}{|c|}{ Matéria seca da parte aérea ( $\mathrm{g}$ por planta) } \\
\hline Controle & $3,26 \mathrm{Aa}$ & $2,60 \mathrm{Aab}$ & $2,98 \mathrm{Aa}$ & $2,89 \mathrm{Aa}$ & $1,92 \mathrm{Ab}$ & $2,85 \mathrm{Aab}$ \\
\hline \multirow[t]{2}{*}{ AB219 } & $3,20 \mathrm{Aa}$ & $2,72 \mathrm{Aab}$ & $3,26 \mathrm{Aa}$ & $2,64 \mathrm{Aab}$ & $2,01 \mathrm{Ab}$ & $2,80 \mathrm{Aab}$ \\
\hline & \multicolumn{6}{|c|}{ Matéria seca total (g por planta) } \\
\hline Controle & 3,52Aa & $2,86 \mathrm{Aab}$ & $3,28 \mathrm{Aa}$ & $3,08 \mathrm{Aab}$ & $2,14 \mathrm{Ab}$ & $3,21 \mathrm{Aa}$ \\
\hline $\mathrm{AB} 219$ & $3,41 \mathrm{Aa}$ & $2,96 \mathrm{Aab}$ & $3,71 \mathrm{Aa}$ & $2,80 \mathrm{Aab}$ & $2,25 \mathrm{Ab}$ & $3,25 \mathrm{Aab}$ \\
\hline
\end{tabular}

(1)Médias seguidas da mesma letra, minúscula na linha e maiúscula na coluna, não diferem entre si a 5\% de probabilidade pelo teste de Tukey; para a análise estatística os dados médios de quatro repetições foram transformados em $\sqrt{\mathrm{x}} \cdot{ }^{(2)} 1$ : casca de arroz carbonizada, bagana de carnaúba e vermicomposto; 2: casca de arroz carbonizada, pó de coco e vermicomposto; 3: casca de arroz carbonizada, vermiculita e vermicomposto; 4: casca de arroz carbonizada, bagana de carnaúba e vermiculita; 5: casca de arroz carbonizada e pó de coco; 6: casca de arroz carbonizada e vermiculita. 
aérea (Tabela 3). A absorção deste elemento por abacaxizeiro deve merecer nova investigação, sendo comum seu acúmulo em áreas irrigadas. Efeito positivo do cloreto de sódio, até a concentração de $12,5 \mathrm{mM}$, também foi observado na formação de brotos in vitro na cultivar Smooth Cayenne (Medeiros et al., 2001).

Por sua vez, os substratos também influenciaram o acúmulo de nutrientes da parte aérea das plantas
(Tabela 4). O conteúdo de $\mathrm{N}$ foi maior nas plantas crescidas em casca de arroz carbonizada, bagana de carnaúba e vermicomposto (40,88 mg por planta), mas não diferiu dos demais substratos onde estava presente o vermicomposto ou folha de carnaúba. As quantidades de $\mathrm{N}$ fornecidas pela solução nutritiva (9,2 mg por planta) e presentes nos substratos (Tabela 1) dão indicação de que houve outra entrada do elemento no sistema. Considerando que a bacté-

Tabela 4. Conteúdo de nutrientes da parte aérea das mudas micropropagadas de abacaxizeiros Cayenne Champac submetidas à inoculação do isolado de bactéria diazotrófica AB219 e crescidas em diferentes substratos em tubete ${ }^{(1)}$.

\begin{tabular}{|c|c|c|c|c|c|c|}
\hline \multirow[t]{2}{*}{ Tratamento } & \multicolumn{6}{|c|}{ Substratos $^{(2)}$} \\
\hline & 1 & 2 & 3 & 4 & 5 & 6 \\
\hline & \multicolumn{6}{|c|}{$\mathrm{N}$ (mg por planta) } \\
\hline Controle & $39,46 \mathrm{Aa}$ & $26,10 \mathrm{Abc}$ & 29,95Aabc & $36,22 \mathrm{Aab}$ & $15,25 \mathrm{Ad}$ & 22,66 Acd \\
\hline \multirow[t]{2}{*}{ AB219 } & $40,88 \mathrm{Aa}$ & $27,94 \mathrm{Aabc}$ & $30,31 \mathrm{Aabc}$ & $33,59 \mathrm{Aab}$ & $17,19 \mathrm{Ac}$ & $21,92 \mathrm{Abc}$ \\
\hline & \multicolumn{6}{|c|}{ P (mg por planta) } \\
\hline Controle & 5,53Aab & $5,34 \mathrm{Aab}$ & $6,99 \mathrm{Aa}$ & $3,31 \mathrm{Abc}$ & $2,14 \mathrm{Ac}$ & 3,92Aabc \\
\hline \multirow[t]{2}{*}{$\mathrm{AB} 219$} & $5,32 \mathrm{Aab}$ & $5,18 \mathrm{Aab}$ & $6,78 \mathrm{Aa}$ & $3,41 \mathrm{Aab}$ & $2,42 \mathrm{Ab}$ & $3,97 \mathrm{Aab}$ \\
\hline & \multicolumn{6}{|c|}{$\mathrm{K}$ (mg por planta) } \\
\hline Controle & $66,17 \mathrm{Ab}$ & $60,83 \mathrm{Ab}$ & $134,17 \mathrm{Aa}$ & $62,80 \mathrm{Ab}$ & $42,89 \mathrm{Ab}$ & $29,00 \mathrm{Aa}$ \\
\hline \multirow[t]{2}{*}{ AB219 } & $73,60 \mathrm{Ab}$ & $66,84 \mathrm{Ab}$ & $158,49 \mathrm{Aa}$ & $59,82 \mathrm{Ab}$ & $53,20 \mathrm{Ab}$ & $49,66 \mathrm{Aa}$ \\
\hline & \multicolumn{6}{|c|}{$\mathrm{Na}(\mathrm{mg}$ por planta) } \\
\hline Controle & $35,65 \mathrm{Ba}$ & $32,63 \mathrm{Ba}$ & $35,48 \mathrm{Ba}$ & $32,63 \mathrm{Ba}$ & $25,20 \mathrm{Ba}$ & $39,62 \mathrm{Ba}$ \\
\hline \multirow[t]{2}{*}{ AB219 } & $57,63 \mathrm{Aab}$ & $55,59 \mathrm{Aab}$ & $74,68 \mathrm{Aa}$ & $65,20 \mathrm{Aab}$ & $45,09 \mathrm{Ab}$ & $63,54 \mathrm{Aab}$ \\
\hline & \multicolumn{6}{|c|}{$\mathrm{Mg}(\mathrm{mg}$ por planta $)$} \\
\hline Controle & $15,52 \mathrm{Ba}$ & $37,80 \mathrm{Aa}$ & $25,77 \mathrm{Aa}$ & $24,73 \mathrm{Aa}$ & $22,55 \mathrm{Aa}$ & $22,50 \mathrm{Aa}$ \\
\hline \multirow[t]{2}{*}{ AB219 } & $29,07 \mathrm{Aa}$ & $30,92 \mathrm{Aa}$ & $35,16 \mathrm{Aa}$ & $32,99 \mathrm{Aa}$ & $23,27 \mathrm{Aa}$ & $21,69 \mathrm{Aa}$ \\
\hline & \multicolumn{6}{|c|}{$\mathrm{Ca}$ (mg por planta) } \\
\hline Controle & $37,58 \mathrm{Aa}$ & $33,49 \mathrm{Aa}$ & $28,66 \mathrm{Ba}$ & $26,29 \mathrm{Aab}$ & $13,28 \mathrm{Ab}$ & $22,05 \mathrm{Aab}$ \\
\hline \multirow[t]{2}{*}{$\mathrm{AB} 219$} & $30,90 \mathrm{Aab}$ & $32,44 \mathrm{Aab}$ & $39,43 \mathrm{Aa}$ & $32,66 \mathrm{Aab}$ & $18,71 \mathrm{Ab}$ & $28,81 \mathrm{Aab}$ \\
\hline & \multicolumn{6}{|c|}{ S (mg por planta) } \\
\hline Controle & $8,14 \mathrm{Aa}$ & $5,10 \mathrm{Aa}$ & $8,33 \mathrm{Aa}$ & $5,90 \mathrm{Aa}$ & $4,79 \mathrm{Aa}$ & $6,46 \mathrm{Aa}$ \\
\hline \multirow[t]{2}{*}{$\mathrm{AB} 219$} & $8,79 \mathrm{Aa}$ & $6,59 \mathrm{Aa}$ & $10,87 \mathrm{Aa}$ & $6,89 \mathrm{Aa}$ & $6,50 \mathrm{Aa}$ & $7,40 \mathrm{Aa}$ \\
\hline & \multicolumn{6}{|c|}{$\mathrm{Cu}(\mu \mathrm{g}$ por planta $)$} \\
\hline Controle & $27,48 \mathrm{Aa}$ & $20,96 \mathrm{Aa}$ & $27,89 \mathrm{Aa}$ & $23,60 \mathrm{Aa}$ & $10,07 \mathrm{Ab}$ & $19,72 \mathrm{Aab}$ \\
\hline \multirow[t]{2}{*}{ AB219 } & $28,00 \mathrm{Aab}$ & $24,17 \mathrm{Aab}$ & $31,85 \mathrm{Aa}$ & $19,02 \mathrm{Abc}$ & $13,59 \mathrm{Ac}$ & $21,58 \mathrm{Aabc}$ \\
\hline & \multicolumn{6}{|c|}{$\mathrm{Fe}(\mu \mathrm{g}$ por planta $)$} \\
\hline & $347,51 \mathrm{Aa}$ & $252,63 \mathrm{Aa}$ & $305,74 \mathrm{Aa}$ & $313,15 \mathrm{Aa}$ & $169,48 \mathrm{Ab}$ & $354,00 \mathrm{Aa}$ \\
\hline \multirow[t]{2}{*}{ AB219 } & $309,74 \mathrm{Aab}$ & $222,41 \mathrm{Abc}$ & $445,60 \mathrm{Aa}$ & $279,12 \mathrm{Abc}$ & $164,26 \mathrm{Ac}$ & $338,57 \mathrm{Aab}$ \\
\hline & \multicolumn{6}{|c|}{ Mn ( $\mu \mathrm{g}$ por planta) } \\
\hline Controle & $182,20 \mathrm{Aa}$ & $139,15 \mathrm{Aa}$ & $159,03 \mathrm{Aa}$ & $182,20 \mathrm{Aa}$ & $183,04 \mathrm{Aa}$ & $182,74 \mathrm{Aa}$ \\
\hline \multirow[t]{2}{*}{ AB219 } & $143,04 \mathrm{Aa}$ & $126,23 \mathrm{Aa}$ & $222,00 \mathrm{Aa}$ & $225,37 \mathrm{Aa}$ & $160,75 \mathrm{Aa}$ & $304,42 \mathrm{Aa}$ \\
\hline & \multicolumn{6}{|c|}{ Zn ( $\mu \mathrm{g}$ por planta) } \\
\hline Controle & $318,18 \mathrm{Aa}$ & $414,19 \mathrm{Aa}$ & $448,15 \mathrm{Aa}$ & $472,15 \mathrm{Aa}$ & $281,25 \mathrm{Aa}$ & $367,84 \mathrm{Aa}$ \\
\hline AB219 & $446,05 \mathrm{Aa}$ & $412,10 \mathrm{Aa}$ & $405,42 \mathrm{Aa}$ & $377,13 \mathrm{Aa}$ & $302,41 \mathrm{Aa}$ & $396,03 \mathrm{Aa}$ \\
\hline
\end{tabular}

(1)Médias seguidas da mesma letra, minúscula na linha e maiúscula na coluna, não diferem entre si a $5 \%$ de probabilidade pelo teste de Tukey; para análise estatística os dados médios de quatro repetições foram transformados em $\sqrt{\mathrm{x}} \cdot{ }^{(2)} 1$ : casca de arroz carbonizada, bagana de carnaúba e vermicomposto; 2: casca de arroz carbonizada, pó de coco e vermicomposto; 3: casca de arroz carbonizada, vermiculita e vermicomposto; 4: casca de arroz carbonizada, bagana de carnaúba e vermiculita; 5: casca de arroz carbonizada e pó de coco; 6: casca de arroz carbonizada e vermiculita. 
ria utilizada no experimento é fixadora de $\mathrm{N}$, o que ficou comprovado pela redução do acetileno em meio semi-sólido JNFb, e que bactérias diazotróficas similares à utilizada para a inoculação nas mudas também foram detectadas nas raízes das plantas controles (Tabela 2), não deveria ser descartada a hipótese da fixação biológica do $\mathrm{N}_{2}(\mathrm{FBN})$ pelo abacaxizeiro associado com o AB219.

Pelas variações dos teores de outros elementos na parte aérea das plantas (Tabela 4), o substrato com casca de arroz carbonizada, vermiculita e vermicomposto foi o melhor. Este substrato também favoreceu o crescimento das plantas (Tabela 3) e apresentou boa agregação (Tabela 2), permitindo sugerir o seu uso na aclimatação de mudas micropropagadas do abacaxizeiro Cayenne Champac.

\section{Conclusões}

1. Os abacaxizeiros Cayenne Champac beneficiamse da associação com o isolado de bactéria diazotrófica $\mathrm{AB} 219$.

2. A presença de bactéria diazotrófica reduz a mortalidade de mudas durante a fase de aclimatação.

3. O substrato formulado com a mistura de casca de arroz carbonizada, vermiculita e vermicomposto, na proporção volumétrica $1: 1: 1$, constitui alternativa para aclimatação de mudas micropropagadas do abacaxizeiro em tubete.

4. O emprego de bactéria diazotrófica diminui o tempo de aclimatação das mudas micropropagadas, antecipando sua transferência para o campo.

\section{Referências}

AGRIANUAL: anuário da agricultura brasileira. São Paulo: FNP Consultoria, 2002. 536 p.

BALDANI, V. L. D. Efeito da inoculação de Herbaspirillum spp. no processo de colonização e infeção de plantas de arroz: ocorrência e caracterização parcial de uma bactéria diazotrófica. 1996. $238 \mathrm{f}$. Tese (Doutorado em Ciência do Solo) - Universidade Federal Rural do Rio de Janeiro, Seropédica, 1996.

BEVIVINO, A.; SARROCCO, S.; DALMASTRI, C.; TABACCHIONI, S.; CANTALE, C.; CHIARINI, C. Characterization of free-living maize rhizosphere population of Burkholderia cepacia: effect of seed treatment on disease suppression and growth promotion of maize. FEMS Microbiology Ecology, Amsterdam, v. 27, p. 225-237, 1998.

CHAVES, J. C. M.; CAVALCANTI JUNIOR, A. T.; CORREIA, D.; SOUZA, F. X. de; ARAÚJO, C. A. T. Normas de produção de mudas. Fortaleza: EmbrapaCNPAT, 2000. 37 p. (Documentos, 41).

DEMATTÊ, J. B. I.; DEMATTÊ, M. E. S. Estudos hídricos com substratos vegetais para o cultivo de orquídeas epífitas. Pesquisa Agropecuária Brasileira, Brasília, v. 31 , n. 11 , p. $803-813$, nov. 1996.

DÖBEREINER, J. History and new perspectives of diazotrophs in association with non-leguminous plants. Symbiosis, Rehovolt, v. 13, p. 1-13, 1992.

DÖBEREINER, J.; BALDANI, V. L. D.; BALDANI, J. I. Como isolar e identificar bactérias diazotróficas de plantas não-leguminosas. Brasília: Embrapa-SPI/ Embrapa-CNPAB, 1995. 60 p.

FAO (Roma, Itália). FAOSTAT Agricultura Data. Disponível em: $<$ http://apps1.fao.org/servlet/XteServlet.jrun? Areas $=\% 3$ E $862 \&$ Items $=574 \&$ Elements $=51 \&$ Years $=2001 \&$ Format $=$ Table $\&$ Xaxis $=$ Years $\&$ Yaxis $=$ Countries $\&$ Aggregate $=\&$ Calculate $=\&$ Domain $=$ SUA $\&$ ItemTypes $=$ Production.Crops.Primary $\&$ Language $=\&$ UserName $>$. Acesso em: 12 nov. 2002.

FEUSER, S.; NODARI, R. O. N.; GUERRA, M. P. Eficiência comparativa dos sistemas de cultura estacionária e imersão temporária para a micropropagação do abacaxizeiro. Revista Brasileira de Fruticultura, Jaboticabal, v. 23, p. 6-10, 2001.

FITCHET, M. Clonal propagation of Queen and Smooth Cayenne pineapple. Acta Horticulturae, Nelspruit, v. 275, p. 261-266, 1990

FOLLIOT, M.; MARCHAL, J. Influence du support de culture sur la vitesse de croissance in vitro des plantes d'ananas emphase d'acclimatation. Fruits, Paris, v. 45, p. $367-376,1990$.

HOAGLAND, D. R.; ARNON, D. T. The water culture method for growing plants without soil. Berkeley: California Agriculture Experiment Station, 1950. 32 p. (University of California. Circular, 347).

KANG, Y.; CARLSON, R.; THARPE, W.; SCHELL, M. A. Characterizations of genes involved in biosynthesis of a novel antibiotic from Burkholderia cepacia $\mathrm{BC} 11$ and their role in biological control of Rhizoctonia solani. Applied and Environmental Microbiology, Washington, v. 64, p. $3939-3947,1998$. 
LEIFERT, C.; CASSELLS, A. C. Microbial hazards in plant tissue and cell cultures. In Vitro Cellular Development Biology - Plant, Columbia, v. 37, p. 133-138, 2001.

MATOS, A. P. de. Pineapple fusariosis in Brazil: an overview. Fruits, Paris, v. 42, p. 417-422, 1987.

MEDEIROS, D. N. de; MACEDO, C. E. C. de; ALOUFFA, M. A. I. Efeito do $\mathrm{NaCl}$ sobre a multiplicação in vitro de abacaxizeiro (Ananas comosus (L.) Merril). Revista Brasileira de Fruticultura, Jaboticabal, v. 23, p. $1-5,2001$

MINAMI, K. A pesquisa em substrato no Brasil. In: KAMPF, A. N.; FERMINO, M. H. (Ed.). Substrato para plantas: a base da produção vegetal em recipientes. Porto Alegre: Gênesis, 2000. p. 159-162.

MURASHIGE, T.; SKOOG, F. A revised medium for rapid growth and bioassays with tobacco tissue cultures. Physiologia Plantarum, Copenhagen, v. 15, p. 473-497, 1962.

RANDING, O.; MEDEIROS, C. A. B.; SPERANDIO, C. A. Efeito da desinfestação do solo pelo uso de energia solar sobre nematóides. Nematologia Brasileira, Piracicaba, v. 22, p. 1-11, 1998.

REINHARDT, D. H. R. C. Manejo e produção de mudas de abacaxi. Informe Agropecuário, Belo Horizonte, v. 19, p. 13-19, 1998.

ROSA, M. de F.; SANTOS, F. J. de S.; MONTENEGRO, A. A. T.; ABREU, F. A. P. de; CORREIA, D.; ARAÚJO, F. B. S. de. Caracterização do pó da casca de coco verde usado como substrato agrícola. Fortaleza: EmbrapaCNPAT, 2001. 6 p. (Comunicado Técnico, 54).

SFALANGA, A.; DI CELLO, F.; MUGNAI, L.; TEGLI, S.; FANI, R.; SURICO, G. Isolation and characterization of a new antagonist Burkholderia strain from rhizosphere of healthy tomato plants. Research in Microbiology, Paris, v. 150, p. 45-59, 1999.

SILVA, F. C. (Org.). Manual de análises químicas de solos, plantas, e fertilizantes. Brasília: Embrapa-SCT/ Embrapa-CNPS/Embrapa-CNPTIA, 1999. 370 p.

SOUZA, F. X. de. Materiais para formulação de substratos na produção de mudas e no cultivo de plantas envasadas. Fortaleza: Embrapa-CNPAT, 2001. 21 p. (Documentos, 43).

TAPIA-HERNÁNDEZ, A.; BUSTILLOS-CRISTALES, M. R.; JIMENEZ-SALGADO, T.; CABALLEROMELLADO, J.; FUENTES-RAMIRES, L. E. Natural endophytic occurrence of Acetobacter diazotrophicus in pineapple plants. Microbial Ecology, New York, v. 39, p. 49-55, 2000.

TEIXEIRA, J. B.; CRUZ, A. R. R.; FERREIRA, F. R.; CABRAL, J. R. Biotecnologia aplicada à produção de mudas: produção de mudas micropropagadas de abacaxi. Biotecnologia, Ciência e Desenvolvimento, Brasília, v. 3, p. 42-47, 2001.

WEBER, O. B.; BALDANI, J. I.; DÖBEREINER, J. Bactérias diazotróficas em mudas de bananeira. Pesquisa Agropecuária Brasileira, Brasília, v. 35, n. 11, p. 2277 2285 , nov. 2000

WEBER, O. B.; BALDANI, V. L. D.; TEIXEIRA, K. R. S.; KIRCHHOF, G.; BALDANI, J. I.; DÖBEREINER, J. Isolation and characterization of diazotrophic bacteria from banana and pineapple plants. Plant and Soil, Dordrecht, v. 210, p. 103-113, 1999.

YAMADA, Y.; KATSURA, K.; KAWASAKI, H.; WIDYASTUTI,Y.; SAONO, S.; SEKI, T.; UCHIMURA, T.; KOMAGATA, K. Asaia borogensis gen. nov., sp. nov.: an unusual acetic acid bacterium in the alpha-Proteobacteria. International Journal of Systematic and Evolutionary Microbiology, Reading, v. 50, p. 823-829, 2000. 